\title{
Statistical Analysis of Papers Published by Teachers in Hubei Business College
}

\author{
Guihong Pei ${ }^{1,}$, Jing Zhang ${ }^{2, b}$ \\ ${ }^{1}$ School of Architectural Economics and Engineering Management, Hubei Business College, Wuhan \\ 430073, China \\ ${ }^{2}$ School of Civil Engineering and Architecture, Southwest Petroleum University, Chengdu 610500, \\ China. \\ 5750769297@qq.com, ${ }^{b}$ lovelydzj@qq.com
}

Keywords: Hubei Business College; Superstar Discovery System; papers; Statistical Analysis

Abstract: Papers published by teachers of Hubei Business College from 2007 to 2017 are counted by means of Super Star Discovery System. The quantity of journal articles and conference papers, research theme, collection condition of core journals, the journal catalogs, subject classification, author's paper quantity and foundation papers have been analyzed. It revealed the present situation of published papers in Hubei Business College, providing reference for Hubei Business College.

\section{Introduction}

The publication of college faculty dissertations can reflect the teachers' ability of scientific research and also reflect the level of scientific research in schools. In order to know more about the publication of teachers' essays in Wuhan University of Light Industry, this article uses the data of "Superstar Discovery System" to analyze the statistical analysis of the papers published by Wuhan Light Industry University from 2007 to 2017.

\section{Data collection}

All data are from "Super Star Discovery System", select Advanced Search, "Journal Type" check "Journal + Conference Papers", "Author Institution" = "Hubei Business College or Business College of Hubei University of Science and Technology", exact match, year selection 2007 --2017, and then refined search, the search results for the 1278 articles, of which 1241 journal articles, conference papers 20. 


\section{Result Analysis}

\subsection{Journal and Conference Articles Analysis}

Journal papers and conference papers play a complementary role in academic exchange. Journal papers are relatively complete and mature reports of research and are easy to be archived. However, conference papers are experts and scholars who express their initial ideas and collect feedback from peers to improve further research reports. From 2007 to 2017, the number of journal articles published by Hubei Business School teachers is shown in Fig.1. The number of published papers generally rose from 2007 to 2015, and the number of journal articles published was nearly 270 in 2015. The number of journal papers fluctuated between 2014 and 2017, but the total number was more than 200.

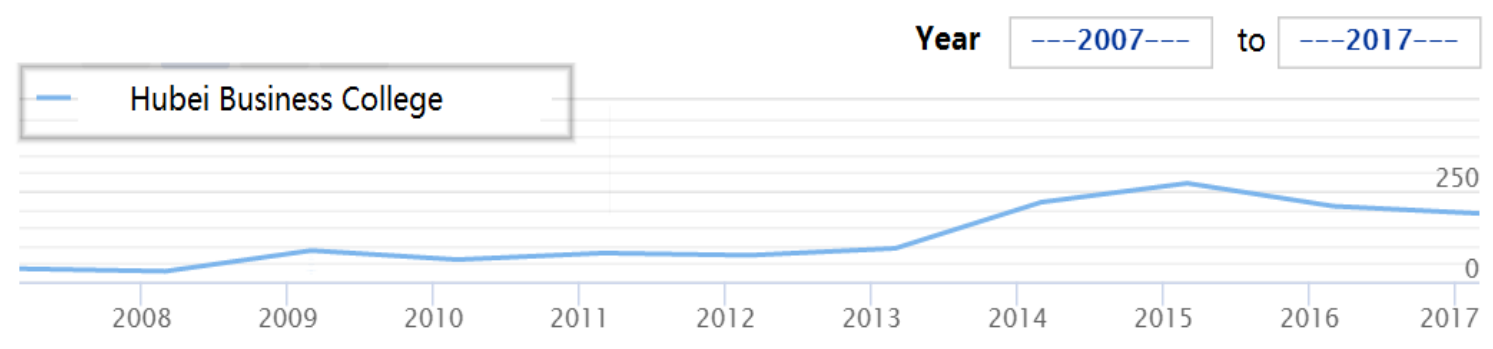

Fig. 1 Journal article number change curve

From 2007 to 2017, the number of conference papers published by Hubei Business College teachers is shown in Fig.2. As can be seen from the figure, only the total number of conference papers published in 2008 exceeded 10, and the number of papers published in other years was 0 . This shows that the university paid insufficient attention to the exchange of academic conferences.

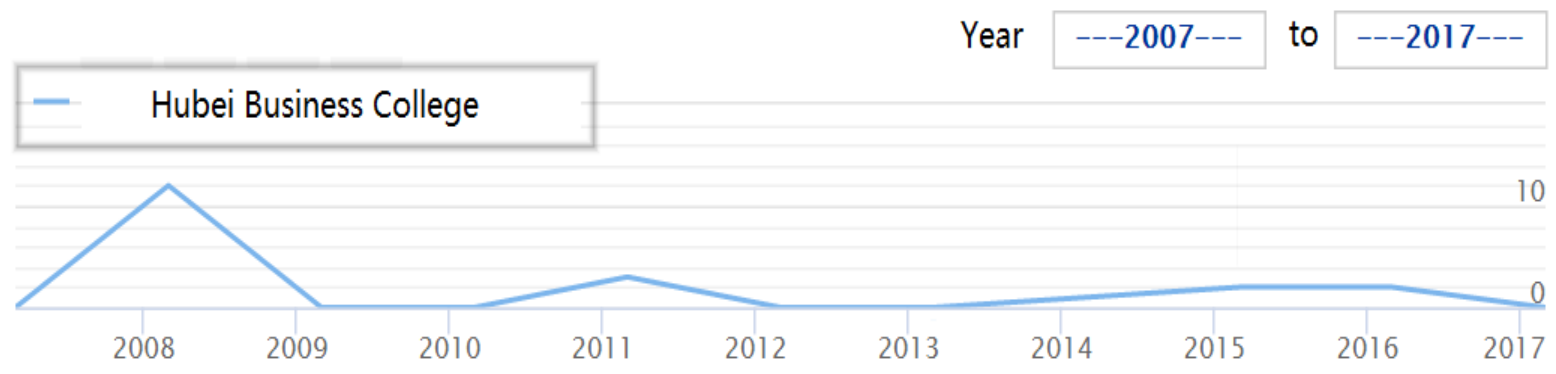

Figure 2 Conference article number change curve

\subsection{Research Topic Analysis}

In order to investigate the main contents of the articles published by teachers of Hubei Business College, the keywords of the retrieved documents were analyzed, and the statistical tables of appearance frequency of main keywords (Table 1) were obtained. As can be seen from the data in Table 1, the contents of the articles published by teachers of Hubei Business College mainly focus on the fields of student management, English education and teaching reform. 
Table 1 Three Scheme comparing

\begin{tabular}{ccc}
\hline No. & Keywords & Frequency \\
\hline 1 & independent college & 81 \\
2 & College English & 38 \\
3 & Teaching Reform & 35 \\
4 & English Teaching & 29 \\
5 & colleges and universities & 29 \\
6 & Ideological \& political & 28 \\
7 & education & 27 \\
8 & Teaching pattern & 24 \\
9 & Undergraduate & 20 \\
10 & ideology and politics & 19 \\
11 & Pollege English teaching & 18 \\
12 & Teactical teaching & 17 \\
13 & Business English & 17 \\
14 & Teaching & 13 \\
15 & Library & 13 \\
\hline
\end{tabular}

\subsection{Core Journal Statistics (Fig 3)}

Core periodicals are an important basis for academic evaluation and research evaluation. As can be seen from Table 2, Hubei Business College teachers published 81 core journals from 2007 to 2017. There are very few papers published in SCI, EI journals.

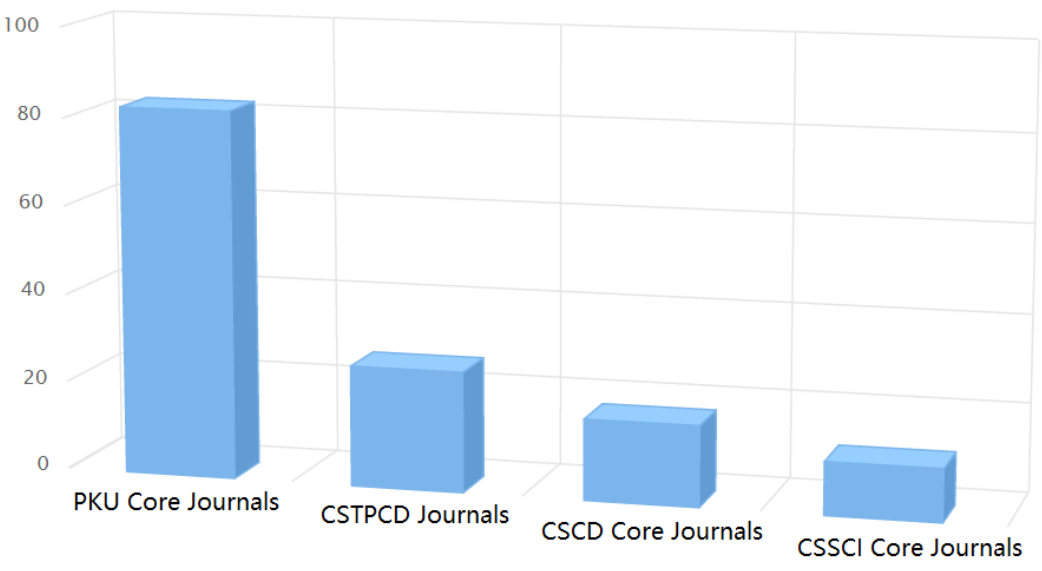

Figure 3 Core Journal Distribution

\subsection{Chinese Subject Classification Statistics}

Hubei Business College is approved by the Ministry of Education approved the establishment of a full-time general undergraduate university, a comprehensive university integrates multidisciplinary development including economics, management, arts, literature and engineering. The number of papers published in various disciplines are: culture, science, education, sports (385); economics (209); 
Industrial Technology (209); language, writing (154); art (108); Literature (47); Politics and Law (14); Mathematical Sciences and Chemistry (14); Transportation (12); General Social Science (7); History and Geography (6); Environmental Science and Safety Science (6); Philosophy and religion (3); Astronomy and Earth Science (3); Natural Science (2); Marxism and Leninism, Mao Zedong Thought and Deng Xiaoping Theory (1).

\subsection{Publication statistics}

Hubei Business College published 1241 papers distributed in a variety of publications, Table 2 lists the top 21 publications. It can be seen from Table 4 that the papers published by Hubei Business Institute are mainly distributed in journals related to economy, commerce, trade and higher education.

Table 2 The occurrence frequency of the main key words

\begin{tabular}{|c|c|c|}
\hline No. & Publication name & Number \\
\hline 1 & Contemporary economy & 36 \\
\hline 2 & Campus English & 30 \\
\hline 3 & Reading Digest & 19 \\
\hline 4 & Science Education Guide & 17 \\
\hline 5 & Literary life & 16 \\
\hline 6 & Wise & 14 \\
\hline 7 & Software Guide & 14 \\
\hline 8 & Exam Weekly & 13 \\
\hline 9 & English Square & 13 \\
\hline 10 & China's collective economy & 12 \\
\hline 11 & Chinese Business Theory & 12 \\
\hline 12 & Overseas English & 12 \\
\hline 13 & Science Review & 11 \\
\hline 14 & Read and write & 11 \\
\hline 15 & Technology Business Monthly & 10 \\
\hline 16 & Literary education & 10 \\
\hline 17 & Technology Information & 9 \\
\hline 18 & Fujian tea & 9 \\
\hline 19 & Modern commerce industry & 9 \\
\hline 20 & Science and education Wenhui & 9 \\
\hline & & \\
\hline
\end{tabular}

\subsection{Author Statistics}

The number of papers published reflects the author's number of scientific research, but also an important basis for determining the core author. Fig.4 shows the most published author distribution. 


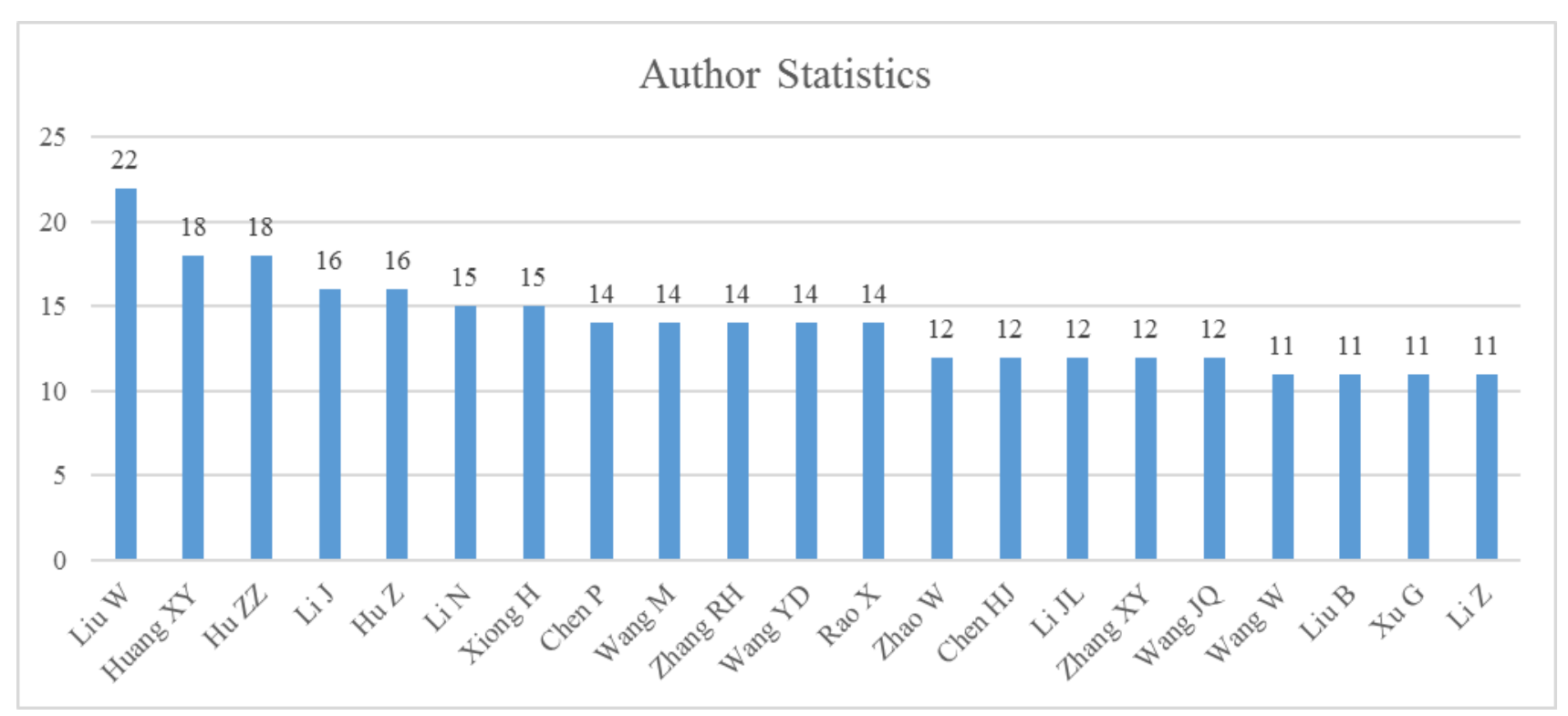

Figure 4 Statistics by author's number of papers published

\section{Conclusion}

(1) The number of journal articles in Hubei Business College shows a slight increase at first and then a slight decrease, and finally tends to be stable in the fluctuation; the conference papers show an increasing trend and a decreasing trend at first.

(2) The content of the thesis published by teachers in this school mainly focuses on the field of undergraduate education, economy, commerce, industrial technology and English teaching.

(3) The proportion of papers published in core journals is not high, and the level of published journals is generally low.

(4) The fund of the school thesis is very low. Mainly from provinces and cities research fund, need to strengthen ministerial and national research projects for the project.

\section{References}

[1] Barilan J. Web of Science with the Conference Proceedings Citation Indexes: the case of computer science [J]. Scientometrics, 2010, 83(3):809-824.

[2] Shi Di, Liu Jianjun. Literature Statistical Analysis of Gas Hydrate Research in China. International Journal of Applied Engineering Research, 2017, 12(7):1254-1259

[3] Liu Jianjun, Wu Mingyang, Zhu Zhengwen, Shao Zuliang. A Study on the Mechanical Properties of the Representative Volume Element in Fractal Porous Media. Geofluids, 2017, UNSP 7905218.

[4] Liu Jianjun, Shao Zuliang, Wu Mingyang, Zheng Yongxiang. Heat and Mass Transfer Analysis of Depressurization-induced Hydrate Decomposition with Different Temperatures of Over- and Underburden. Journal of Natural Gas Science and Engineering. 2017, Vol.44, 65-76.

[5] Song Rui, Liu Jianjun, Cui Mengmeng. A new method to reconstruct structured mesh model from micro-computed tomography images of porous media and its application. International Journal of Heat and Mass Transfer, 2017, Vol.109:705-715.

[6] Wu Yuliang, Liu Jianjun, Fan Kaixiang. Study on Release Mechanism and Control Technology of Hydrogen Sulfide Gas in Coal Mine. Journal of Residuals Science \& Technology. 2016, 13(S2):S73-S83. 